\title{
ORGANIC PERSONAL CARE COSMETICS: BEHAVIOR OF CHOICE AND CONSUMPTION
}

\author{
Gražina Šniepiené ${ }^{1}$, Rita Jankauskienè $\dot{2}^{2}$
}

\begin{abstract}
:
Background. The researchers have shown that even small doses of some chemical substances in cosmetics, when absorbing and accumulating in the body, can damage the skin and provoke various diseases. Therefore, the choice of organic cosmetics with certified ingredients can contribute to human health and nature conservation.

The survey aimed to determine behavior of choice and consumption of organic cosmetic products according to the consumers' socio-demographic characteristics.

Methods. A quantitative survey was performed, a validated questionnaire and data collection method - a written survey were used. Survey sample -335 people ( $38.5 \pm 4.07$ years old). Data analysis using SPSS 26.0 was performed, calculated percentage frequencies, mean, Pearson's Chi-Square test to detect statistically significant differences, and Spearman's correlation was used.

Results. The study found that more than half of women used organic cosmetics. A significant difference $(\mathrm{p}<0.05)$ was found with age, which showed that organic products were used significantly more often by 26-35-year-old individuals and between the sexes $(p=0.05)$. It was found that facial skincare, body care, and hair care products are the most commonly used, while pregnancy skincare products are the least commonly used. Consumers indicated the reasons for choosing these products: health benefits, natural composition, non-polluting environment during production, and recyclability of packaging. Most often, respondents do not use such cosmetics due to unclear labeling and the higher prices of these products. Sufficient and complete information on the label, a reliable and well-known producer are considered to be the most important identification criteria. In contrast, a special point of sale, clear and attractive promotional/visual information being the least important.

Conclusions. The study has shown that organic cosmetics consumption varies between consumers of different gender and age. However, the education and income of consumers did not affect this choice. The type of organic cosmetic products differs according to consumer socio-demographic characteristics - gender, age, education, and income. In addition, the results of the study suggest that special attention should be paid to the choice of cosmetic products for women during pregnancy and products for skincare of infants and young children. Main reasons for choosing organic cosmetics were health benefits, natural composition, non-polluting production and recyclable packaging. However, unclear labeling and higher price are the main reasons for not choosing organic cosmetics. The identification criteria of organic cosmetics varied by consumer gender, income, and education, but the age didn't have any meaning. This study has found that consumers lack knowledge about eco-labeling of personal care cosmetic products. Further research is needed in this area.
\end{abstract}

UDC Classification: 646.7, DOI: https://doi.org/10.12955/pmp.v2.190

Keywords: organic personal care products, choice, consumption.

\section{Introduction}

Recently, the consumer has a great personal care and cosmetics choices. Cosmetic products help create the desired appearance; however, improper choice or use can damage the skin and provoke various diseases (Zirwas, 2019; Nowaka et al., 2018). Many chemical substances in cosmetics applied or sprayed on the skin are absorbed and accumulate in the body. Researchers have shown that even small doses of them entering the human body can cause health problems (Juliano, Magrini, 2017; Kim et al., 2016; Giulivo et al., 2016). Growing consumer concern for health and environment has resulted in increased attention towards organic cosmetics and beauty products with healthiest quality ingredients (Amberg, Fogarassy, 2019; Kapoor et al., 2019; Matić, Puh, 2016; Fonseca-Santos et al., 2015).

Along with the growing awareness of people in the field of environmental care, changes in the cosmetics industry can also be observed (Jaśniewski et al., 2018). The changing of consumers' by becoming more sustainable and healthier in their lifestyles forms the rebirth of natural cosmetics. Production of natural and organic cosmetics has grown in recent years (Barbulova et al., 2015; Matic, 2015). The ecological cosmetic market is expanding all over the world (Akter, Islam, 2020).

To overcome consumer demand as well as the regulators, various companies and producers are beginning to design, develop and sell natural and organic cosmetics products (Syahrul, Mayangsari,

\footnotetext{
${ }^{1}$ Klaipeda State University of Applied Sciences, Faculty of Health Science, Physiotherapy and Beauty Therapy Department; Klaipeda University, Faculty of Health Sciences, Department of Nursing; Lithuania, g.sniepiene@kvk.lt

${ }^{2}$ Klaipeda State University of Applied Sciences, Faculty of Health Science, Physiotherapy and Beauty Therapy Department; Klaipeda University, Faculty of Health Sciences, Department of Medical Technologies; Lithuania, r.jankauskiene@kvk.lt
} 
2020). Despite targeting long-term profitability and environment-friendly sustainability, there is a need to understand consumers' demographics such as age, gender, income, and others before deciding to use green cosmetics (Kapoor et al., 2019). Some studies found that demographic factors are one of the most influencing factors in predicting consumer behavior towards organic cosmetic products (Kapoor et al., 2019; Matic, Puh, 2016). However, there is little research about consumer behavior of choice and consumption regarding organic personal care cosmetic products according to the socio-demographic characteristics of consumers.

The aim of the study was to determine behavior of choice and consumption of organic cosmetic products according to the consumers' socio-demographic characteristics.

Research question: does the behavior of choice and consumption of organic cosmetics depend on consumers' socio-demographic characteristics?

\section{Literature review}

For many people, sustainability and cosmetics are two distinct terms (Amberg, Magda, 218). Sustainable consumption behaviour is a type of consumption that tries to balance current and future generations' social, economic and environmental needs (Rizkalla, Erhan, 2020). Natural and organic cosmetics have made use of the sustainability trend (Cinelli et al., 2019). The producers of natural and biochemical cosmetics try to avoid synthetic components, and carbon dioxide emission is also lower in manufacturing. The manufacturers have green chemical processes during production that include sustainable production methods (Amberg, Magda, 2018).

The standards for organic products are confirmed by a certified logo that marks all organic products. There are several certification agencies, and each one defines its own guidelines for certification and labeling. Acknowledged cosmetic certificates in Europe include the German BDIH, the French Cosmebio and Ecocert, the Italian Icea, and the English Soil Association. Due to the cooperation between mentioned organisations, COSMOS (COSMetics Organic Standard) was established in 2010 to unify the labeling rules of natural cosmetics in Europe (Amberg, Magda, 2018). The certification aims to check the ingredients, processes, production, storage of raw materials, packaging, labeling, use of energy resources and waste management, and the certification of producers to ensure the quality of the final product. Which means, the certification agencies impose standards that the production industry should fulfil to be able to ensure the final product quality (COSMOS-standard, 2018).

The green consumer is concerned about the environment and the sustainability, and they have certain characteristics and preferences when they buy organic and natural cosmetics (Fonseca-Santos et al., 2015). Age, gender, education level, income level is considered to be the most important demographic factors that have a significant relationship with environmental behavior (Chekima et al., 2015).

\section{The basic terms}

Natural products are formulated from natural resources, meaning that it doesn't use coloring additives, chemical and other non-natural substances. While organic products have a more strict definition where the product's ingredients must not contain toxic pesticides or chemical substances (Amberg, Fogarassy, 2019). In organic cosmetics, at least $95 \%$ of the formulation components are organic raw material with extraction certificates or raw materials that follow strict production, extraction, purification, and processing standards. These raw materials can be obtained through certificated crops and extraction, it's fundamental that they are biodegradable and that they preserve the most natural chemical characteristics. Organic raw material is always natural (Fonseca-Santos et al., 2015). Organic cosmetics are multifaceted constructions usually aimed at the following: environmental conservation, minimization of polluting, responsible usage of non-renewable resources, and preservation of fauna and species. Organic or environmentally friendly products are mainly products defined as non-hazardous to natural resources and renewable. They can basically be used without harming the environment (Syahrul, Mayangsari, 2020; Lin et al., 2018).

Organic and natural cosmetics show qualitative similarity into formulations; however they are quantitative different. They may not contain synthetic or semi-synthetic raw materials in the formulations, with some exceptions. They may contain raw material derived from natural products with allowed processes. They need to contain raw materials with organic origin, which varies in the amount present in natural or organic products (Fonseca-Santos et al., 2015). Organic/bio /ecological cosmetic 
products that are not unhealthy for consumers, which had not been tested on animals, do not contain genetically modified ingredients, and have not been irradiated (Amberg, Magda, 2018).

The different adjectives like eco, organic, natural, made from herbs and plants practically are identical, meaning the same. They are all cosmetics made from natural materials that are natural, floral, can be found in nature like algae or minerals. The term "eco-friendly" means that there is a concern in the production process, the life cycle, and other factors, like the use of clean technologies, the rational use of natural resources, product certifications, and biodegradable packaging (Fonseca-Santos et al., 2015).

\section{Research hypotheses}

Today, the healthier way of living trends does affect the rising consumer's interest and perception in products containing natural substances, including cosmetic products (Matic, Puh, 2016; Syahrul, Mayangsari, 2020). Young people who are more open towards innovation are more likely to purchase organic cosmetics (Kaliyadan et al., 2020; Kapoor et al., 2019). The study aims what socio-demographic characteristics people tend to consume organic cosmetics. The first hypothesis, therefore, is:

H.1. Use of organic cosmetics vary between the consumers with different socio-demographic characteristics

Personal care products - the daily use of cosmetics to cleanse, deodorize, and beautify the face and body. Many traditional cosmetics contain controversial ingredients that lack safety (Kim et al., 2016). As an alternative - organic cosmetics are recommended, emphasizing their health benefits (Ghazali et al., 2017; Fonseca-Santos et al., 2015). The most sought-after products are organic skin care followed by naturalbased hair care and cosmetics (make-up). The share of oral care is half the hair care. Half of the demand for oral care is the demand for other cosmetics (Amberg, Magda, 2018). The study aims at what type of organic cosmetic products tend to consume individuals with different socio-demographic characteristics. This leads to hypothesis 2 :

H.2. Types of organic cosmetic products vary between consumers with different socio-demographic characteristics.

Many studies have tried to discover what factors can affect sustainable consumption behavior (Rizkalla, Erhan, 2020). To understand consumer choice behavior, it is important to recognize how consumers make decisions, and the criteria used to choose the selected product over another (Syahrul, Mayangsari, 2020). Several studies undertaken on the purchasing behavior towards organic cosmetics found that ecoawareness,_environmental knowledge, and health concerns are the main factors influencing purchasing of such types of cosmetics (Akter et al., 2020; Rizkalla, Erhan, 2020; Kaliyadan et al., 2020; Kapoor et al., 2019; Nguyen et al., 2019; Ghazali et al., 2017).

The use of sustainable compostable or biodegradable materials for cosmetic packaging is a major challenge and an opportunity for sustainability. One of the factors in choosing cosmetics is recyclable packaging (Cinelli et al., 2019; Jaśniewski et al., 2018; Amberg, Magda, 2018; Lin et al., 2018; FonsecaSantos et al., 2015; Besier, 2015). Green cosmetics are often more expensive, which may result in less consumers being able to buy them (Kaliyadan et al., 2020; Amberg, Fogarassy, 2019; Joshi, 2015).

Some studies show consumers do not trust the labeling on the package and remain skeptical towards organic cosmetics (Lin et al., 2018; Joshi, 2015). The study aims to determine the reasons for choosing/not choosing organic cosmetics for individuals with different socio-demographic characteristics. Therefore, hypothesis 3 is:

H.3. Reasons for choosing/not choosing organic cosmetics vary between the consumers with different socio-demographic characteristics.

How can the consumer decide if a certain cosmetic product is organic or not? The main feature that confirms the organic product standard is the certified logo, which marks all organic products (Amberg, Magda, 2018). In order to identify organic cosmetics, a quicker and simpler method is looking for certificates. As the logos of different certificates cannot be displayed on the cosmetic products without permission, we can say that they certify that the cosmetics were made from natural certified components (Amberg, Magda, 2018; Fonseca-Santos et al., 2015). Research shows that a reliable and well-known manufacturer is very important for consumers (Kapoor et al., 2019). The study aims what organic cosmetics identification criteria for individuals with different socio-demographic characteristics are. This leads to hypothesis 4 : 
H. 4. Organic cosmetics identification criteria vary between the consumers with different sociodemographic characteristics.

\section{Data and methodology}

The survey data was collected during May of 2019-March of 2020 in three specialized stores selling cosmetics of Klaipeda city (Lithuania). Consumers who reported using organic cosmetics in the last 3 months were interviewed. A quantitative survey was performed, data collection method - written survey. The research instrument: an original questionnaire created by the study authors and based on existing scientific researchers; was compromised of 6 multiple choice questions and 4 sociodemographic characteristics. The questionnaire consisted of the following parts: demographic questions (gender, age, income, and education); questions revealing the organic cosmetics consumption; reasons for choosing/not choosing and identification criteria of organic cosmetics (Table 1). The questionnaire consisted of nominal and ordinal variables. The Likert's scale was used to evaluate the ordinal variables (1 - not important at all, 5 - very important).

\begin{tabular}{|c|c|c|}
\hline Questions and question groups & $\begin{array}{l}\text { Number of } \\
\text { responses/statements }\end{array}$ & Measurement scale/ Variants of answer \\
\hline Organic cosmetics consumption & ( & $\begin{array}{l}\text { Nominal; Yes; No; } \\
\text { Don't know }\end{array}$ \\
\hline Used type of organic cosmetics & 7 & Nominal \\
\hline Reasons for choosing organic cosmetics & 10 & $\begin{array}{l}\text { Ordinal, } 1 \text { - not important at all, } \\
5 \text { - very important }\end{array}$ \\
\hline Reasons not choosing organic cosmetics & 5 & $\begin{array}{l}\text { Ordinal, } 1 \text { - not important at all, } \\
5 \text { - very important }\end{array}$ \\
\hline Organic cosmetics identification criteria & 6 & $\begin{array}{l}\text { Ordinal, } 1 \text { - not important at all, } 5 \text { - very } \\
\text { important }\end{array}$ \\
\hline Purchasing places & 8 & Nominal \\
\hline \multicolumn{3}{|l|}{ Socio-demografic characteristics } \\
\hline Gender & 2 & Nominal (male, female) \\
\hline Average monthly income & 3 & Ordinal (intervals) \\
\hline Education & 3 & Ordinal \\
\hline Age & 3 & Ordinal (intervals) \\
\hline
\end{tabular}

Cronbach's Alpha coefficient was calculated for the internal reliability of the questionnaire, its values for all ordinal variables were greater than 0.8 , which indicates good reliability of the questionnaire. The Cronbach's Alpha values for the individual parts are given (Table 2).

\begin{tabular}{|l|l|l|}
\hline Table 2. Indicators of internal reliability of the questionnaire \\
\hline Groups of statements & Number of statements & Cronbach's Alfa \\
\hline Reasons for choosing organic cosmetics & 10 & 0.855 \\
\hline Reasons for not choosing organic cosmetics & 5 & 0.801 \\
\hline Organic cosmetics identification criteria & 6 & 0.879 \\
\hline Source: Authors & \multicolumn{2}{l}{} \\
\hline
\end{tabular}

Survey sample -335 people ( $56.9 \%$ women and $43.1 \%$ men). The average age of the respondents was $38.5 \pm 4.07$ years. According to age, respondents are divided into three groups: $26-35 ; 36-45$, and $46-$ 55 years. The majority of participants of the study were $36-45$ years old respondents $(61 \%)$, the least $46-55$ years (12\%), 26-35 years - 27\%. Respondents' education - secondary, professional higher, and university higher. According to education, the majority of respondents had higher (professional and university) education, which accounted for $83.7 \%$, secondary education - $16.3 \%$ of all respondents. The monthly income of the respondents varies from less than 240 Euros to more than 1000 Euros, the latter accounting for $86 \%$ of all respondents. The average monthly income was $617.88 \pm 391.32$ Euros.

The basic ethical principles of the study were followed: informed and voluntary consent to participate in the study; ensuring anonymity and confidentiality of information received; avoidance of harm to respondents. 
Data analysis was performed using the social research statistics program SPSS 26.0. For all variables, were calculated percentage frequencies, for ordinal - mean. The Pearson's Chi-Square test was used to detect statistically significant differences among different groups, and the Spearmen's correlation coefficient was used to estimate the relationship between the ordinal variables. The significance level selected was $\mathrm{p}<0.05$.

\section{Results and discussion}

\section{Organic cosmetics consumption according to consumer socio-demographic characteristics}

The study found that more than half (58.4\%) of women consumed organic cosmetics in the last 3 months, which was 1.78 times more than those who did not use this type of cosmetics. In comparison, among men, those who did not use it were found to be about 1.5 times more than those who used organic cosmetics. After calculating the Chi-square $(\chi 2)$ criterion between respondents with different sociodemographic characteristics, a significant difference $(\mathrm{p}<0.05)$ was found in groups of age and gender $(\mathrm{p}=0.05)($ Table 3$)$.

\begin{tabular}{|c|c|c|c|c|c|c|c|}
\hline \multicolumn{2}{|c|}{ Socio - demographic characteristics } & $\begin{array}{l}\text { Used } \\
\%\end{array}$ & $\begin{array}{l}\text { Didn't use } \\
\%\end{array}$ & $\begin{array}{l}\text { Don't know } \\
\%\end{array}$ & $\chi^{2}$ & $d f$ & $p$ \\
\hline \multirow[t]{2}{*}{ Gender } & Women & 58.4 & 32.7 & 8.8 & \multirow[t]{2}{*}{7.27} & \multirow[t]{2}{*}{6} & \multirow[t]{2}{*}{$0.05^{*}$} \\
\hline & Men & 35.3 & 52.9 & 11.8 & & & \\
\hline \multirow{3}{*}{$\begin{array}{l}\text { Monthly } \\
\text { income } \\
\text { (Euro) }\end{array}$} & To 500 & 45.5 & 38.6 & 15.9 & \multirow[t]{3}{*}{5.53} & \multirow[t]{3}{*}{4} & \multirow[t]{3}{*}{0.24} \\
\hline & $500-1000$ & 63.5 & 31.7 & 4.8 & & & \\
\hline & 1001 and more & 52.2 & 39.1 & 8.7 & & & \\
\hline \multirow[t]{3}{*}{ Age (years) } & $26-35$ & 73.3 & 17.8 & 8.9 & \multirow[t]{3}{*}{13.4} & \multirow[t]{3}{*}{6} & \multirow[t]{3}{*}{ 0.04* } \\
\hline & $36-45$ & 43.4 & 49.1 & 7.5 & & & \\
\hline & $46-55$ & 46.7 & 33.3 & 20 & & & \\
\hline \multirow[t]{3}{*}{ Education } & Secondary & 51.5 & 39.4 & 9.1 & \multirow[t]{3}{*}{9.02} & \multirow[t]{3}{*}{4} & \multirow[t]{3}{*}{0.06} \\
\hline & Professional higher & 41.7 & 45.8 & 12.5 & & & \\
\hline & University higher & 71.4 & 22.4 & 6.1 & & & \\
\hline
\end{tabular}

Based on the primary research results in Sweden, India, and Hungary, young women are more open toward organic natural cosmetics than men (Atker, Islam, 2020; Kapoor et al., 2019; Amberg, Fogarassy, 2019). This study showed that women aged 26-35 years more commonly use organic cosmetics. Another study in Lithuania showed that educated middle-aged women with middle income are the most ecofriendly when related to purchases (Pikturnienè, Mackelaite, 2013). It has been established in this study that $58,4 \%$ of the interviewed Lithuanian women purchased environmentally-friendly cosmetic products, compared with $50 \%$ of British and $63 \%$ of Sweden women (Atker, Islam, 2020; Linet et al., 2018).

\section{Type of organic cosmetic products according to consumer socio-demographic characteristics}

The most commonly used organic cosmetics were identified during the study (Figure 1). It was found that facial care products (70\% of all respondents), body care (55\%), and hair care (53\%) are the most commonly used, while pregnancy skincare products $(15 \%)$ are the least commonly used. Comparing the frequency of choosing a certain type of organic cosmetics products within different socio-demographic characteristics, according to the "chi-square" $(\chi 2)$ criterion, significant differences were found $(p<0.05)$, which showed that facial skincare products are used almost twice as often by women than men ( $p$ $<0.005$ ). Body care products are used about 1.5 times more often by persons with higher university education than by those with higher professional and 2 times than by those with secondary education $(p$ $<0.01)$. Ecological skincare products for infants and children are used 3 times more often by those with higher incomes $(\mathrm{p}<0.007)$ and about 2 - 4 times more often by those aged 26-35-than in other age groups $(\mathrm{p}<0.01)$. Natural decorative cosmetics are used significantly more often by women $(\mathrm{p}<0.02)$ and persons with higher university and higher professional education than by men and with secondary education $(\mathrm{p}<0.007)$. 
Adoption of organic products is worth especially relevant for people of more vulnerable age groups babies, young children, or older people, especially the sick ones, also for pregnant women. However, our study revealed the worrying fact that Lithuanian consumers rarely consumed organic products for pregnant and baby skincare. Infants and young children are at greater risk of disruption of the barrier function, toxicity, and contact irritation or allergy (Geer et al., 2017; Giulivo et al., 2016). Special precautions should be taken when using cosmetics in women who are pregnant or breastfeeding. Some cosmetic substances that enter the systemic circulation tend to accumulate in the body, pass through the placental barrier, and enter the breast milk (Geer et al., 2017; Haraux et al., 2017). Ingredients in cosmetic products can have side effects on the baby: some preservatives and antimicrobials, fragrances, surfactants, UV filters, and other substances (Giulivo et al., 2016).

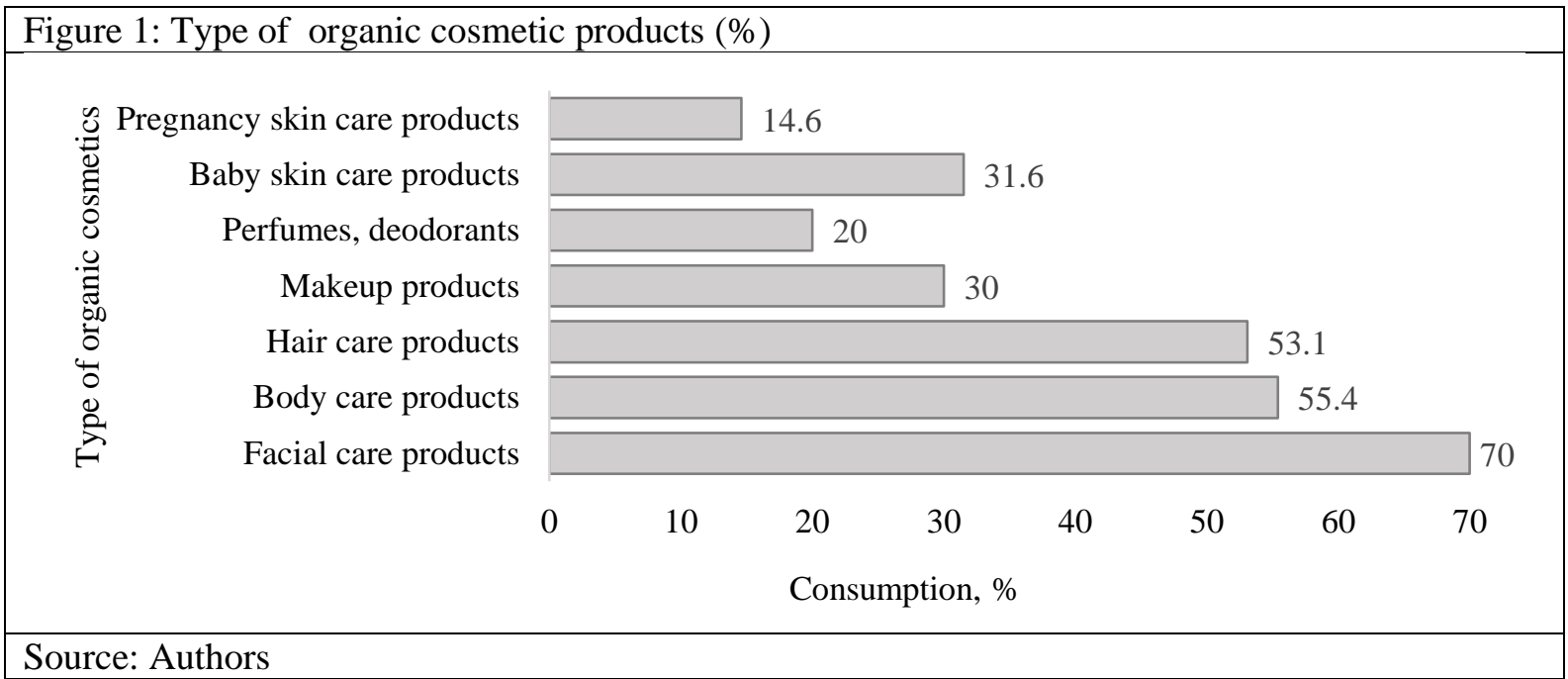

Although facial skincare products are in the greatest demand in the market of organic cosmetics (Amberg, Magda, 2018), however, according to some studies, organic products are often purchased for skincare of children.

During the study, respondents indicated that the most common places of organic cosmetics purchases are pharmacies (55\% of respondents) and specialized cosmetics stores (51\%), most seldom - internet $(16 \%)$, cosmetic distributors (18\%), and beauty salons (19\%). After calculating the Chi-square $(\chi 2)$ criterion, significant differences $(\mathrm{p}<0.05)$ were found between the places of purchase of organic cosmetics according to the socio-demographic characteristics of consumers. It was found that persons with higher university and higher professional education purchase products in specialized cosmetics stores about 2 times more often than those with secondary education ( $\mathrm{p}<0.01)$. In pharmacies, organic cosmetics are purchased about 1.5 times more often by people aged 25-35 and 46-55 persons than 3645 -year persons $(\mathrm{p}<0.003)$, and persons with secondary education $(\mathrm{p}<0.02)$. Women buy organic cosmetics in beauty salons ( $\mathrm{p}<0.04)$. In other cases, no significant differences were found ( $p>0.05$ ). According to other researchers, most organic cosmetic products are purchased online, especially by young consumers. Online availability contains items like ease of buying, ready comparison among products, multiple payment options, ease of exchange and return policies (Kapor et al., 2019).

Reasons for choosing/not choosing organic cosmetics according to consumer socio-demographic characteristics

Consumers who reported using organic cosmetics in the last 3 months indicated motives for choosing these products: health benefits, natural composition, non-polluting environment during production, and recyclability of packaging (Figure 2). It is interesting to note that respondents with health and skin problems and organic lifestyle followers chose organic cosmetics the least.

The Spearman correlation test between the reasons for choosing organic cosmetics and the different socio-demographic characteristics found that the recyclable product package was significantly more important $(\mathrm{r}=0.4 ; \mathrm{p}<0.001)$, whereas the promotion measures $(\mathrm{r}=-0.5 ; \mathrm{p}<0.001)$ and recommendations of specialists and acquaintances $(r=-0.4 ; p<0.001)$ were significantly less important factors for higherincome earners. It was also found that older people choose organic cosmetics regardless of whether they are followers of an organic lifestyle $(r=-0.3 ; p<0.003)$. No significant correlations between the 
importance of other reasons for choosing organic cosmetics and socio-demographic characteristics were found ( $p>0.05$ ) (Table 4). The Chi-square $(\chi 2)$ criterion was used to determine gender differences, and no statistically significant differences were found $(p>0.05)$.

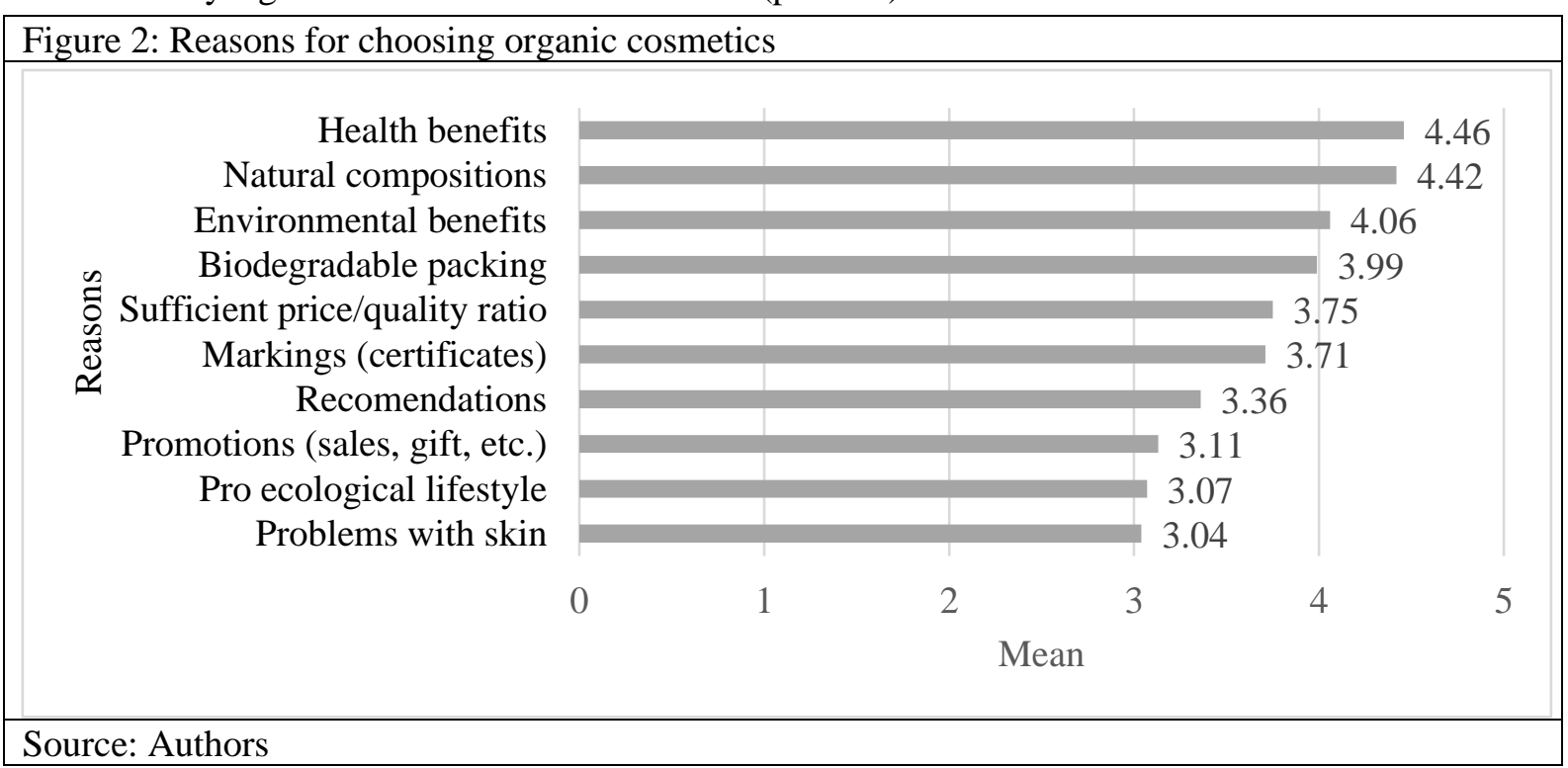

Table 4. The Spearmen's correlation among reasons for choosing organic cosmetics and sociodemographic characteristics

\begin{tabular}{|c|c|c|c|c|}
\hline \multicolumn{2}{|l|}{ Factors } & $\begin{array}{l}\text { Monthly income } \\
\text { (Euro) }\end{array}$ & Age (years) & Education \\
\hline \multirow[t]{2}{*}{ Health benefits } & $R$ & 0.14 & -0.12 & 0.11 \\
\hline & $P$ & 0.22 & 0.3 & 0.33 \\
\hline \multirow[t]{2}{*}{ Natural composition } & $R$ & 0.07 & -0.08 & 0.07 \\
\hline & $P$ & 0.52 & 0.48 & 0.54 \\
\hline \multirow{2}{*}{$\begin{array}{l}\text { Sufficient price/quality } \\
\text { ratio }\end{array}$} & $R$ & -0.12 & -0.07 & 0.001 \\
\hline & $P$ & 0.29 & 0.55 & 0.99 \\
\hline \multirow[t]{2}{*}{ Labelling (certificates) } & $R$ & 0.16 & -0.06 & 0.03 \\
\hline & $P$ & 0.14 & 0.57 & 0.79 \\
\hline \multirow[t]{2}{*}{ Environmental benefits } & $R$ & 0.17 & -0.09 & 0.02 \\
\hline & $P$ & 0.12 & 0.4 & 0.86 \\
\hline \multirow{2}{*}{ Biodegradable packing } & $R$ & 0.35 & 0.05 & 0.15 \\
\hline & $P$ & $0.001 * *$ & 0.63 & 0.18 \\
\hline \multirow[t]{2}{*}{ Recommendations } & $R$ & -0.44 & -0.13 & -0.21 \\
\hline & $P$ & $0.00 *$ & 0.23 & 0.05 \\
\hline \multirow{2}{*}{$\begin{array}{l}\text { Promotions (sales, gifts, } \\
\text { etc.) }\end{array}$} & $R$ & -0.46 & 0.005 & 0.21 \\
\hline & $P$ & $0.00 *$ & 0.97 & 0.06 \\
\hline \multirow[t]{2}{*}{ Pro ecological lifestyle } & $R$ & -0.09 & -0.32 & 0.08 \\
\hline & $P$ & 0.43 & $0.003 *$ & 0.48 \\
\hline \multirow[t]{2}{*}{ Problems with skin } & $R$ & 0.18 & -0.11 & 0.19 \\
\hline & $P$ & 0.79 & 0.42 & 0.09 \\
\hline \multicolumn{5}{|c|}{$\begin{array}{l}* * \text { the difference is statistically significant }(\mathrm{p}<0.01) \\
* \text { the difference is statistically significant }(\mathrm{p}<0.05)\end{array}$} \\
\hline \multicolumn{5}{|c|}{ Source: Authors } \\
\hline
\end{tabular}

Studies in the UK showed consumer attitudes toward organic product attributes, including functions, ingredients, packaging, fragrance, and price, influenced purchase behavior. Therefore, consumers pay more attention to functions rather than detailed ingredients (Lin et al., 2018). Consumers won't use natural and organic cosmetics, if they're not as effective as their chemical counterparts (Amberg, Fogarasy, 2019).

Many studies found that consumers prefer products with biodegradable, recyclable or returnable packaging instead of plastic packaging, which in the capacity of their nature are wastes causing 
environmental damages (Cinelli et al., 2019; Kardos et al., 2019; Jaśniewski et al., 2018; Amberg, Magda, 2018; Lin et al., 2018; Fonseca-Santos et al., 2015; Besier, 2015).

This study showed that persons having health and skin problems and pro-ecological lifestyle follower's organic cosmetics choose the least. Other authors also showed a phenomenon exists where consumers do not necessarily buy green products even if they have knowledge of green products and know their attributes (Wang et al., 2019).

The most common reasons why people did not choose organic cosmetics were identified. Most often, respondents do not use such cosmetics due to unclear labeling (distrust that they are truly organic) and the higher prices of these products (Figure 3).

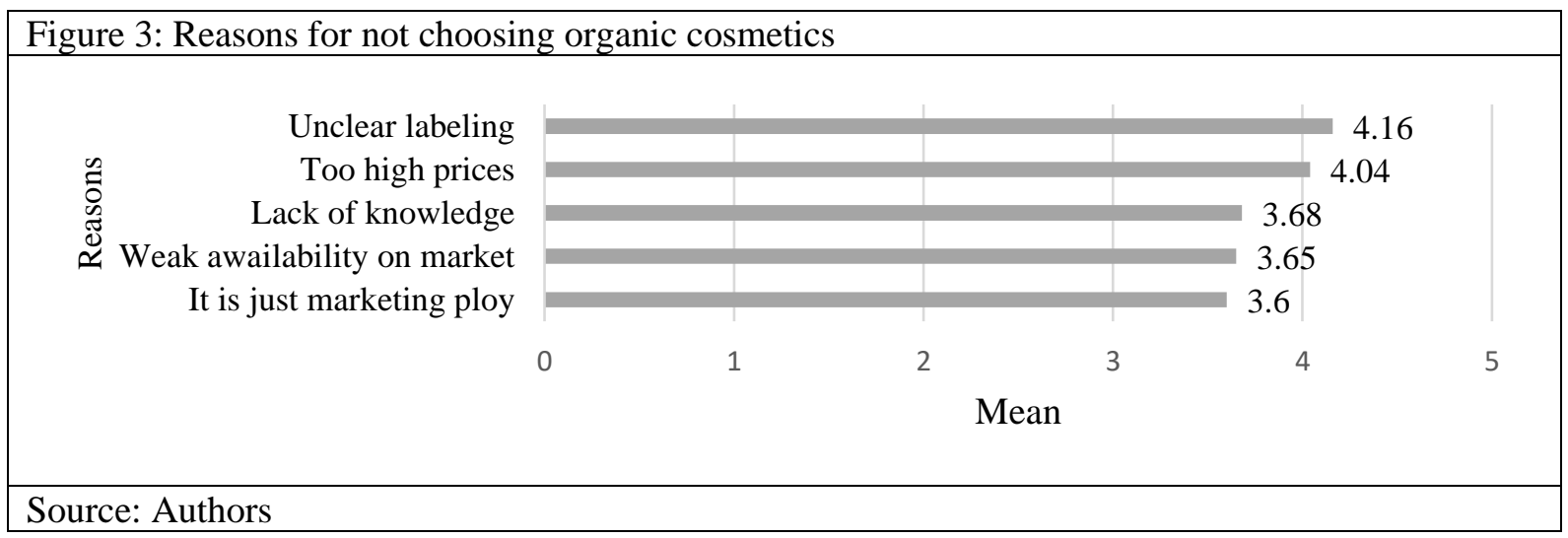

However, no statistically significant correlations were found between the motives for not choosing of organic products within individual socio-demographic characteristics. In all cases $p>0.05$. Although, the price of organic cosmetics is slightly higher than conventional, it is due to the unique production method and high-quality standards. This study showed that a higher price often become an obstacle to buy organic cosmetics. The higher price is in some kind as an inhibitor to shift from conventional to organic cosmetic products (Kaliyadan et al., 2020). Study conducted by Joshi (2015) also showed that high price negatively influences green purchase intention and behavior. However, some studies showed that conscious educated, wealthy people are willing to pay extra, since they consider conserving both their own health and the environment an important factor (Syahrul, Mayangsari, 2020; Amberg, Fogarasy, 2019; Kapoor et al., 2019).

Another inhibitor towards organic cosmetics is the lack of information about the ingredients of the product (Kapoor et al., 2019). Although the interest in ecological brands for Lithuanian consumers is comparable to world trends, they are still not able to differentiate between various levels of ecological labeling, terms "green", "environmentally friendly", and "ecological", or recognize a "green brainwashing", when producers manipulate emphasizing only one ecological element or natural ingredients (Pikturnienè, Mackelaitė, 2013). This research shoved in most cases, respondents do not use organic cosmetics for mistrust, it's really organic cosmetics. These findings are confirmed by other studies. The study in the UK also showed most respondents were unclear about the standards of green cosmetics. They do not trust the labeling on the package and do not believe in the effects of cosmetics (Lin et al., 2018). The consumers do not trust the information provided and remain skeptical towards the manufacturing, labeling, and certification procedures of various (Joshi, 2015). British consumers find it difficult to select green cosmetic products. Consumers are confused since the concept of 'natural' and 'organic' varies and is inconsistent (Lin et al., 2018). The strategy of cosmetics businesses should focus on increasing consumers' consciousness and inclination to favoreco-certified products. Marketers should work on the labeling and certification of the green cosmetics (Kapoor et al., 2019).

Identification criteria of organic cosmetic products according to consumer socio-demographic characteristics

The study identified the criteria by which consumers recognize organic products. Sufficient and complete information on the label, a reliable and well-known producer, and the indications of organic production are considered to be the most important identification criteria, whereas a special point of sale, clear and attractive promotional/visual information being the least important. Spearman's correlation results between the identification criteria according to the Likert scale and individual socio- 
demographic characteristics showed that organic production labels, sufficient and detailed information on the label, and clear and attractive promotional/visual information are of significant importance for women. A special point of sale and an eco-certificate is significantly more important for those with higher incomes and higher professional education (Table 5).

Table 5. Correlation coefficients between different identification criteria of organic products and socio-demographic characteristics of consumers

\begin{tabular}{|c|c|c|c|c|c|}
\hline \multicolumn{2}{|l|}{ Identification criteria of organic products } & Gender & $\begin{array}{l}\text { Average } \\
\text { monthly } \\
\text { income }\end{array}$ & Age & Education \\
\hline \multirow[t]{2}{*}{ Eco labels are indicated } & $r$ & $-0.22 *$ & 0.15 & -0.08 & 0.09 \\
\hline & $p$ & 0.01* & 0.09 & 0.35 & 0.3 \\
\hline \multirow[t]{2}{*}{ Reliable and well-known manufacturer } & $r$ & -0.1 & 0.09 & -0.14 & 0.05 \\
\hline & $p$ & 0.26 & 0.31 & 0.12 & 0.55 \\
\hline \multirow[t]{2}{*}{ Special trading place } & $r$ & -0.02 & 0.19* & -0.02 & $0.2 *$ \\
\hline & $p$ & 0.8 & 0.03* & 0.81 & 0.03* \\
\hline \multirow[t]{2}{*}{ Sufficient and complete information on the label } & $r$ & $-0.2 *$ & 0.03 & -0.1 & 0.1 \\
\hline & $p$ & $\mathbf{0 . 0 3 *}$ & 0.72 & 0.25 & 0.25 \\
\hline \multirow[t]{2}{*}{ Eco certificate } & $r$ & -0.03 & $0.2 *$ & -0.05 & 0.17 \\
\hline & $p$ & 0.74 & 0.02* & 0.57 & 0.06 \\
\hline \multirow[t]{2}{*}{ Clear and engaging promotional/visual information } & $r$ & $-0.23 *$ & -0.04 & -0.02 & 0.04 \\
\hline & $p$ & 0.01* & 0.66 & 0.84 & 0.69 \\
\hline
\end{tabular}

*the difference is statistically significant $(\mathrm{p}<0.05)$

Source: Authors

Consumers must be clear the main feature that confirms the organic product standard is the certified logo, which marks all organic products. The certification aims to check the ingredients, processes, production, storage of raw materials, packaging, labeling, use of energy resources and waste management, and producers' certification to ensure the quality of the final product (Amberg, Magda, 2018; Fonseca-Santos et al., 2015).

With growing consumer demand for eco-innovative products, greener extraction techniques, a new green emulsifying system, new green-active ingredients are found to be potential alternatives, especially for cosmetic manufacturing industries (Gubitosa et al., 2019; Panda, Manickam, 2019; Semenzato et al., 2018; González-Minero, Bravo-Díaz, 2018). The time has come for a new generation of cosmetics characterized by quality, safety, and efficacy. Sustainability and human safety are the most relevant issues for all cosmetic products (Barbulava et al., 2015). We need to transform our current culture of consumption by informing, raising awareness, educating, changing consumer behavior, adopting new eco-innovative biotechnology towards sustainability, and ecopreneurship achieve a green cosmetics industry for our future generation.

\section{Conclusion and recommendations}

The study has shown that organic cosmetics consumption varies between the consumers of different gender and age. However, the education and income of consumers did not affect this choice. Types of organic cosmetic products differ according to consumer socio-demographic characteristics such as gender, age, education, and income. In addition, the study results suggest that special attention should be paid to the choice of cosmetic products for women during pregnancy and products for skincare of infants and young children.

The main reasons for choosing organic cosmetics were health benefits, natural composition, nonpolluting production, and recyclable packaging. However, unclear labeling and higher price are the main reasons for not choosing organic cosmetics. The identification criteria of organic cosmetics varied by consumer gender, income, and education, but the age didn't have any meaning. The study has found that consumers lack knowledge about eco-labeling of personal care cosmetic products. Further research is needed in this area.

This study has some limitations. Firstly, a convenience sampling survey was conducted, all consumers volunteers were included in the survey, regardless of the different groups, especially vulnerable consumer groups (children, the elderly, and pregnant women). Further studies with different consumer groups and a bigger sample size would add to the generalizability of the findings. 
Another limitation might emerge due to geographical restrictions in this research. The study was based on respondents of Klaipeda city, which cannot fully represent cosmetics choice and consumption in Lithuania as a whole. It is advisable to extend the investigations to a larger territorial unit. We suggest that the research should be conducted in other areas of Lithuania as well. Future research is also encouraged to conduct including organic cosmetic producers, and this could expand knowledge on environmentally responsible behavior.

\section{References}

Akter, S., Islam, S. (2020). Factors influencing the attitude of women towards purchasing green products: an explorative case study of organic cosmetics in Sweden. Journal of Consumer Sciences, 48, 38-64, ISSN 0378-5254

Amberg, N., Fogarassy, C. (2019). Green Consumer Behavior in the Cosmetics Market. Resources, Resources, 8(3), 137, https://doi.org/10.3390/resources8030137

Amberg, N., Magda, R. (2018). Environmental Pollution and Sustainability or the Impact of the Environmentally Conscious Measures of International Cosmetic Companies on Purchasing Organic Cosmetics. Visegrad Journal on Bioeconomy and Sustainable Development, 7(1), 23-30, https://doi.org/10.2478/vjbsd-2018-0005

Barbulova, A., Colucci, G., Apone, F. (2015). New Trends in Cosmetics: By-Products of Plant Origin and Their Potential Use as Cosmetic Active Ingredients. Cosmetics, 2(2), 82-92, https://doi.org/10.3390/cosmetics2020082

Besier, S. (2015). Generational perceptions of pro-environmental packaging advantages. Schwerpunktthema, 23, 315-322, https://doi.org/ 10.1007/s00550-015-0375-2

Chekima, B., Chekima, S., Wafa, S.A., Igau, O.A., Sondoh, S.L. (2016) Sustainable consumption: the effects of knowledge, cultural values, environmental advertising, and demographics, International Journal of Sustainable Development \& World Ecology, 23(2), 210-220, https://doi.org/ 10.1080/13504509.2015.1114043

Cinelli, P., Coltelli, M.B., Signori, F., Morganti, P., Lazzeri, A. (2019). Cosmetic Packaging to Save the Environment: Future Perspectives. Cosmetic, 6 (2), 26, https://doi.org/10.3390/cosmetics6020026

COSMOS-standard. Cosmetics organic and natural standard. Brussels: Cosmos-standard AISBL, 2018. Available in: https://cosmosstandard.files.wordpress.com/2018/08/cosmos-standard-v3-0.pdf. Accessed on: 2021 March 20.

Fonseca-Santos, B., Corrêa, M.A., Chorilli, M. (2015). Sustainability, natural and organic cosmetics: consumer, products, efficacy, toxicological and regulatory considerations. Brazilian Journal of Pharmaceutical Sciences, 51(1), 17-26, https://doi.org/10.1590/S1984-82502015000100002

Geer, L.A, Pycke, B.F.G., Waxenbauma, J., Sherer, D. M., Abulafia, O., Haldenb, R.U. (2017). Association of birth outcomes with fetal exposure to parabens, triclosan, and triclocarban in an immigrant population in Brooklyn, New York. Journal of Hazardous Materials, 323, 177-183, https://doi.org/10.1016/j.jhazmat.2016.03.028

Ghazali, E., Soon, P.C., Mutum, D.S, Nguyen, B. (2017). Health and cosmetics: Investigating consumers' values for buying organic personal care products. Journal of Retailing and Consumer Services, 39, 154-163, https://doi.org/10.1016/j.jretconser.2017.08.002

Giulivo, M., Lopez de Alda, M., Capri, E., Barceló, D. (2016). Human exposure to endocrine disrupting compounds: Their role in reproductive systems, metabolic syndrome and breast cancer. A review. Environmental Research, 151, 251-264, https://doi.org/10.1016/j.envres.2016.07.011

González-Minero, F.J., Bravo-Díaz, L. (2018). The Use of Plants in Skin-Care Products, Cosmetics and Fragrances: Past and Present. Cosmetics, 5, 50, https://doi:10.3390/cosmetics5030050

Gubitosa, J., Rizzi, V., Fini, P., Cosma, P. (2019). Hair Care Cosmetics: From Traditional Shampoo to Solid Clay and Herbal Shampoo, A Review. Cosmetics, 6, 13, https://doi:10.3390/cosmetics6010013

Haraux, E., Braun, K., Ricard, J., Buisson, P., Stéphan-Blanchard, E., Devauchelle, C., Ricard, J,, Boudailliez, B,, Tourneux, P., Gouron, R., Chardon, K. (2017). Maternal exposure to domestic hair cosmetics and occupational endocrine disruptors is associated with a higher risk of hypospadias in the offspring. Int. J Environ. Res Rublic Health, 14(1), 27, https://doi:10.3390/ijerph14010027

Joshi, Y., Rahman, Z. (2015). Factors Affecting Green Purchase Behaviour and Future Research Directions. International Strategic Management Review, 3(1-2), 128-143, http://dx.doi.org/10.1016/j.ism.2015.04.001

Juliano, C., Magrini, G.A. (2017). Cosmetic Ingredients as Emerging Pollutants of Environmental and Health Concern. A Mini-Review Cosmetics, 4, 11, https://doi:10.3390/cosmetics4020011

Kaliyadan, F., Al Dhafiri, M., Atif, M. (2020). Attitudes toward organic cosmetics: A cross-sectional population-based survey from the Middle East. Journal of Cosmetic Dermatology, https://doi.org/10.1111/jocd.13909

Kapoor, R., Singh, A.B., Misra, R. (2019). Green Cosmetics - Changing Young Consumer Preference and Reforming Cosmetic Industry. International Journal of Recent Technology and Engineering (IJRTE), 8(4), 12932-39, https://doi:10.35940/ijrte.D6927.118419

Kim, K.H., Kabir, E., Jahan, S.A. (2016). The use of personal hair dye and its implications for human health. Environment International, 89-90, 222-227, http://dx.doi.org/10.1016/j.envint.2016.01.018

Lin, Y., Yang, S., Hanifah, H., Iqbal, Q. (2018). An Exploratory Study of Consumer Attitudes toward Green Cosmetics in the UK Market. Adm. Sci., 8, 71, https://doi:10.3390/admsci8040071 
Matić, M., Puh, B. (2016). Consumers' purchase intentions towards natural cosmetics. Ekonomski vjesnik/econviews, 53-64. UDK: 658.89:159.94

Nguyen, T.T.H., Yang, Z., Nguyen, N., Johnson, L.W., Cao, T.K. (2019). Greenwash and Green Purchase Intention: The Mediating Role of Green Skepticism. Sustainability, 11 (9), 2653, https://doi.org/10.3390/su11092653

Nowaka, P.K., Ratajczak-Wronaa, W., Górskab, M., Jabłońskaa, E. (2018). Parabens and their effects on the endocrine system. Molecular and Cellular Endocrinology, 474, 238-251, https://doi.org/10.1016/j.mce.2018.03.014

Panda, D., Manickam, S. (2019). Cavitation Technology—The Future of Greener Extraction Method: A Review on the Extraction of Natural Products and Process Intensification Mechanism and Perspectives. Applied Sciences, 9(4), 766, https://doi.org/10.3390/app9040766

Pikturniene, I., Mackelaite, A. (2013). Attitude formation towards local and international ecological face and body care brands among Lithuanian female consumers. Organizations and markets in emerging economies, 4 (1), 23-42, https://doi:10.15388/omee.2013.4.1.14257 ISSN 2029-4581

Rizkalla, N, Erhan, T.P. (2020). Sustainable Consumption Behaviour in The Context of Millennials in Indonesia - Can Environmental Concern, Self-efficacy, Guilt and Subjective Knowledge Make a Difference? Management: Journal of Sustainable Business and Management Solutions in Emerging Economies, 25(3), 4-53, https://doi.org/10.7595/management.fon.2020.0001

Semenzato, A., Costantini, A., Meloni, M., Maramaldi, G., Meneghin, M., Baratto, G. (2018). Formulating O/W Emulsions with Plant-Based Actives: A Stability Challenge for an Effective Product. Cosmetics, 5, 59, https://doi.org/10.3390/cosmetics5040059

Syahrul, S.A., Mayangsari, L. (2020). A Study of Motives in Choosing Natural Cosmetics among Indonesian Women. Malaysian Journal of Social Sciences and Humanities (MJSSH), 5 (8), 60 71, https://doi.org/10.47405/mjssh.v5i8.464 Wang, H., Ma, B., Bai, R. (2019). How Does Green Product Knowledge Effectively Promote Green Purchase Intention? Sustainability, 11 94), 1193, https://doi.org/10.3390/su11041193

Zirwas, M.J. (2019). Contact Dermatitis to Cosmetics. Clinical Reviews in Allergy \& Immunology, 56, 119-128, https://doi.org/10.1007/s12016-018-8717-9. 